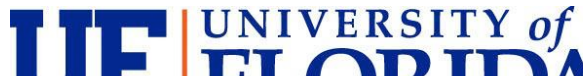 FLORIDA \\ IFAS Extension
}

\section{Descubriendo la Estructura Organizacional ${ }^{1}$}

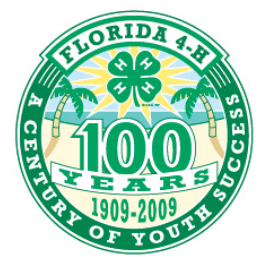

Marilyn N. Norman y Joy C. Jordan²

4-H ha sido posible gracias a los esfuerzos del Servicio Estatal Cooperativo de Investigación, Educación e Instrucción del Departamento de Agricultura de los Estados Unidos (CSREES/USDA) en Washington D.C., del Sistema de Extensión Cooperativa de becas de la Universidad de la Florida, sus instituciones aliadas y los gobiernos de los condados de la Florida. Estos dólares públicos son extendidos por dineros privados recaudados por la Fundación 4-H de la Florida, fundaciones locales, individuos, voluntarios del club 4-H, y el Consejo Nacional de 4-H. Patrocinadores locales, donadores, exalumnos y otros proveen recursos e incentivos para programas educacionales, eventos y reconocimientos.

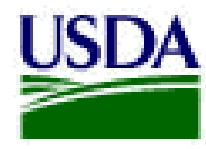

\section{Nacional}

CSREES/USDA (Servicio Estatal Cooperativo de Investigación, Educación e Instrucción del Departamento de Agricultura de los Estados Unidos) es la jefatura nacional del club 4-H y provee este programa con liderazgo nacional. Los administradores nacionales y los líderes del programa identifican problemas a nivel nacional para jóvenes, generan respuestas a nivel del sistema y dirigen los recursos del gobierno a programas relevantes y efectivos para el desarrollo de los jóvenes. (http://www.national4-hheadquarters.gov)

\section{Estado}

IFAS

Las Universidades con Concesión de Tierras en cada estado y las universidades de tribus están aliadas con el CSREES y administran los programas de extensión en su estado. En 1862, el Acta de Morrill concedió tierra y un fondo parcial para el desarrollo de una universidad en cada estado para dar acceso a un nivel más alto de educación a las personas del estado. En 1890, la segunda Acta de Morrill incluyó 17 universidades históricas para personas de color al sistema de Concesión de Tierras. La Equidad en Educación en el Estatus del Acta de Tierras Concedidas de 1994 sumó 30 universidades de tribus al sistema de Concesión de Tierras. Estas instituciones conforman el sistema de Universidades de Concebimiento de Tierras en cada estado. Estas instituciones son el hogar de Los Programas de Desarrollo Juvenil 4-H. Una lista de Universidades de Tierras Concedidas esta disponible en: http://www.csrees.usda.gov/qlinks/partners/statepartners. $\underline{\mathrm{html}}$

En Florida, dos universidades-Universidad de la Florida, una institución de 1862, y Universidad de A \& M, una institución de 1890 - apoya la implementación de los programas 4-H. Cada Universidad de Tierra Concedida tiene una jefatura del estado del club 4-H como el USDA. En la Florida, esta oficina está localizada en IFAS en la Universidad de la Florida. Esta oficina fue establecida en 1963, una combinación de oficinas

1. Este documento 4HS FS101.3-Spn, es una serie del Programa 4-H del Servicio de Extensión Cooperativa de la Florida, Instituto de Alimentos y Ciencias Agrícolas, Universidad de la Florida. Traducido al español por Rafael Arango y Claudia Peñuela. Primera edición: julio de 2009. Por favor visite el sitio en la Web en EDIS http://edis.ifas.ufl.edu.

2. Marilyn Norman, Profesora Asociada en Ciencias de la Familia, la Juventud y la Comunidad y Líder del programa 4-H, y Joy C. Jordan, Profesora Asociada en Ciencias de la Familia, la Juventud y la Comunidad, Instituto de Alimentos y Ciencias Agrícolas, Universidad de Florida, Gainesville.

El Instituto de Alimentos y Ciencias Agrícolas es un empleador que provee Oportunidades Igualitarias, autorizado a proveer investigación, información educativa y otros servicios, únicamente a los individuos e instituciones que operan sin discriminación alguna con relación al credo, color, religión, edad, incapacidad, sexo, orientación sexual, estado civil, nacionalidad, opinión política o afiliaciones. Para más información sobre como obtener otras publicaciones de extensión, comuníquese con la oficina de Servicio de Extensión de su condado. Servicio de Extensión de la Florida / Instituto de Alimentos y Ciencias Agrícolas / Universidad de la Florida / Millie Ferrer, Decano Interino. 
de UF, FAMU y el programa de niñas en ese tiempo en FSU. (http://www.florida4h.org)

\section{Condado}

Cada condado tiene uno o más agentes de 4-H con responsabilidad primaria o compartida sobre el Programa de Desarrollo Juvenil. Algunos condados que incluyen grandes ciudades podrían tener oficinas adicionales y empleados sirviendo solo a esa ciudad. También, en la Florida, las Tribus de los Seminoles emplean un agente 4-H en el condado de Glades. El número telefónico de la oficina de extensión puede ser encontrado en las páginas azules del gobierno de la guía telefónica local. Los fondos del condado son suministrados para apoyar a los empleados y las operaciones en las oficinas locales de 4-H.

Los agentes 4-H, junto a los voluntarios, inician clubes $4-\mathrm{H}$ en comunidades locales y les proveen una variedad de programas, actividades, eventos, y reconocimiento a los jóvenes, a los padres y a los voluntarios.

\section{Fundaciones}

Consejo Nacional 4-H. Esta organización sin ánimo de lucro provee becas, establece programas/iniciativas, diseña y publica currículos y materiales de referencia y crea conexiones fomentando la innovación y el aprendizaje compartido para avanzar el movimiento de desarrollo juvenil 4-H. Esto le ayuda al USDA y al club 4-H a construir un mundo en el que los jóvenes y los adultos aprenden, crecen y trabajan juntos para un cambio positivo. El Consejo está asociado con el 4-H en todos los niveles-nacional, estado y condado. El Consejo esta encargado del Centro Nacional de 4-H en Chevy Chase, MD. (www.fourhcouncil.edu)

Fundación 4-H de la Florida. Esta organización estatal sin ánimo de lucro provee becas para apoyar los programas estatales y locales y funciona como un agente fiscal para el programa 4-H. La fundación 4-H es una Organización de Servicio Directo de la Universidad de la Florida, solicita fondos para programas a nivel estatal y frecuentemente provee becas a nivel de condados, haciendo reconocimientos y dando becas a nivel estatal y apoyando eventos especiales. En la Florida, la Fundación 4-H del Estado funciona como agente fiscal para cuatro campos residenciales.

La fundación 4-H puede ser encontrada en 30\% de los condados. Sin embargo, cuando un condado no tiene su propia fundación, esa identidad funciona de la misma manera proveyendo fondos y apoyos limitados a los esfuerzos del programa del condado. (http://solutionsforyourlife.ufl.edu/4-H/foundation.html)

\section{Cuadro Organizacional}

Nivel Nacional

Departamento de Agricultura de Los Estados

Unidos (USDA): Aprobado en el congreso como la casa de la organización 4-H. Administrado por: La Secretaría de Agricultura de USA: cita política por el presidente.

Servicio Estatal Cooperativo de Investigación, Educación e Instrucción (CSREES): Una de muchas agencias del USDA. Tiene ocho unidades administradas por: El administrador del CSREES.

Familias, 4-H y Nutrición: Una de las ocho unidades del CSREES. Administrada por: El Administrador Diputado del F4-HN.

Desarrollo Juvenil: Una de dos unidades del F4$\mathrm{HN}$ y la Jefatura Nacional del 4-H. Administrada por: El Director de Desarrollo Juvenil.

Líderes del Programa Nacional: Seis líderes del programa proveen el programa y políticas de liderazgo y brindan ayuda financiera asegurando becas y universidades de tierras concedidas.

\section{Nivel Estatal}

Universidades de Tierra Concedida:

Compañeros Estatales y de Tribus con la Cooperativa del Servicio de Extensión. Tiene varias universidades administradas por: El Presidente de la Universidad, junto con los Vicepresidentes de cada facultad o divisiones de la Universidad. La Universidad de la Florida es una universidad de tierra concedida.

Cooperativa del Servicio de Extensión: Es responsable de brindar conocimiento e investigación generada en la universidad para combatir las necesidades básicas de los ciudadanos en comunidades a través del estado. Tiene varios departamentos o unidades. Administradas por: El Director de la Cooperativa de Extensión. La Extensión en la Florida es una parte de UF/IFAS.

\section{Especialistas de Extensión Estatal 1862:}

(posiciones en la facultad) Son responsables de traducir las investigaciones para que sean aplicables y apoyar a los empleados del estado por medio de la enseñanza, asistencia en la preparación de becas, el desarrollo de una hoja de vida y los materiales de soporte. Estos empleados son parte del departamento académico que apoyan de acuerdo a 
su experiencia. Casi todos los especialistas utilizan su tiempo en investigación, enseñanza y extensión.

Especialista de Extensión 1890: lleva programas a condados o regiones del estado donde existen necesidades prioritarias de un programa. Todos los programas se enfocan en las iniciativas nacionales del Sistema de Extensión y proveen asistencia educacional para granjeros con recursos limitados, familias y jóvenes para ayudarles a adquirir habilidades que les mejoren su calidad de vida y sus comunidades.

Especialista de Extensión 1994: lleva el programa a poblaciones y comunidades nativas en ciudades a través del estado. Florida no tiene una Institución 1994.

Especialista de Extensión del Área/Distrito: un grupo estatal de condados que se unen a dar apoyo a los empleados. Estas áreas o distritos tienen oficinas en algunas partes del condado. La Florida no tiene Facultad de Extensión del Distrito 4-H por ahora.

\section{Oficina Estatal 4-H del Desarrollo Juvenil:}

Departamento o unidad responsable de aplicar conocimiento e investigación al crecimiento y desarrollo de los jóvenes en las comunidades a través del estado. Administrada por el Líder de Extensión Estatal 4-H (algunas veces llamado el Asociado o Asistente del Director del Desarrollo Juvenil 4-H) La Oficina Estatal 4-H en la Universidad de la Florida no es un departamento, pero es una unidad directamente bajo el decano de extensión. Los empleados de Extensión de cada departamento de IFAS deben tener un porcentaje de citas para trabajar con audiencias jóvenes.

\section{Extensión de Tribus del Desarrollo Juvenil: Está encargada de llevar conocimiento e investigación relacionada con el crecimiento y desarrollo juvenil a los jóvenes de reservas y comunidades nativas en áreas metropolitanas. Administrada por el Director de Tribus de Extensión del Desarrollo Juvenil. La Florida no tiene una Facultad Tribal.}

\section{Nivel de Condado}

Las universidades de tierra concedidas sirven como audiencias en cada condado en los Estados Unidos a través del sistema de extensión del condado.

Comisionados del Condado: Aprueban los fondos del presupuesto de Extensión. Estas son posiciones gubernamentales elegidas en la Florida. Los Directores de Extensión del Condado trabajan cercanamente con los gobiernos de cada condado para asegurar los fondos de Extensión.

\section{El Comité Consultivo del Condado y el Comité Consultivo del Programa 4-H del Condado:}

Provee consejos, dirección, e implementación de todos los programas de extensión del condado. El grado al cual los agentes del condado son responsables de los comités de extensión, varia de acuerdo a la manera en que los fondos del estado sean distribuidos en los condados de cada estado. Estas son posiciones designadas.

\section{Facultad de Extensión del Condado:}

Responsable de coordinar las necesidades del condado con el estado y la extensión de apoyo del condado y de implementar ofertas de programas apropiados. Usualmente las oficinas del condado consisten en un grupo de agentes del condado; típicamente compuestos de un agente de Agricultura, un agente de Ciencias de la Familia y el Consumidor y un agente del 4-H. Algunos condados grandes podrían tener empleados adicionales para diferentes funciones. Condados más pequeños tienen menos empleados que comparten responsabilidades programáticas o pueden compartir empleados con condados vecinos. Uno de estos agentes servirá como el Director del Condado. Los agentes son responsables como Directores de Extensión del Distrito (DED) y del comité consejero de la extensión del condado. También se provee ayuda del Programa de Líderes Estatales.

Agente 4-H o Empleado 4-H: Se encarga de llevar todos los aspectos del programa de Desarrollo Juvenil 4-H del condado. Los agentes 4-H trabajan con voluntarios, padres, jóvenes, escuelas, y organizaciones en comunidades para proveer oportunidades para que los jóvenes fortalezcan sus habilidades.

Líderes Voluntarios: Adultos y jóvenes mayores quienes sirven como líderes de grupo, líderes de proyectos, consejeros en campamentos, etc. Algunos líderes voluntarios trabajan directamente con jóvenes y otros voluntarios como entrenadores y mentores. 